\begin{tabular}{|c|c|}
\hline 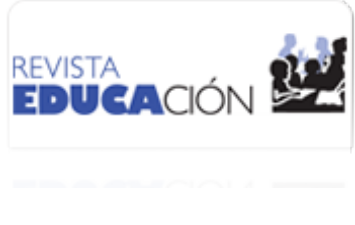 & $\begin{array}{l}\text { Revista Educación } \\
\text { ISSN: 0379-7082 } \\
\text { ISSN: } 2215-2644 \\
\text { revedu@gmail.com } \\
\text { Universidad de Costa Rica } \\
\text { Costa Rica }\end{array}$ \\
\hline
\end{tabular}

\title{
Consideraciones para la formación continua de personal docente universitario
}

\author{
Alanís Jiménez, José Francisco 1 \\ Consideraciones para la formación continua de personal docente universitario \\ Revista Educación, vol. 42, núm. 2, 2018 \\ Universidad de Costa Rica, Costa Rica \\ Disponible en: http://www.redalyc.org/articulo.oa?id=44055139013 \\ DOI: https://doi.org/10.15517/revedu.v42i2.25123
}

Esta obra está bajo una Licencia Creative Commons Atribución-NoComercial-SinDerivar 3.0 Internacional. 


\title{
Consideraciones para la formación continua de personal docente universitario
}

\section{Considerations for Continuing in-service Teaching Training for University Professors}

José Francisco 1 Alanis Jiménez

Universidad Nacional Autónoma de México, México

picoalanis@outlook.com

(iD) http://orcid.org/0000-0002-3092-3397

\author{
DOI: https://doi.org/10.15517/revedu.v42i2.25123 \\ Redalyc: http://www.redalyc.org/articulo.oa?id=44055139013
}

Recepción: 19 Junio 2016

Aprobación: 20 Abril 2018

\section{Resumen:}

Este artículo inicia con un apartado de antecedentes en el que se profundiza sobre el término "formación" y se plantea el objetivo metodológico de "Identificar elementos relevantes para docentes de universidad en relación con dispositivos de formación continua no formal, representándoles a través de un esquema que muestre su articulación con base en el análisis de datos empíricos”. En un siguiente apartado sobre referentes conceptuales se explica de qué manera se pretende generar conocimiento a partir de la reconstrucción articulada propuesta por Zemelman, así como de la teoría fundamentada (Strauss y Corbin). En otro apartado sobre la vía metódica se describe cómo fue recogida la información, principalmente a través de entrevistas semiestructuradas con ocho participantes y dos personas de coordinación de este tipo de dispositivos, distribuidas en tres rondas a lo largo de 22 meses. Un apartado posterior presenta los resultados que perfilan seis conceptos ordenadores: agencia, mercadización, proletarización, introyección, resistencia y procesos formativos. Se aportan ejemplos para ilustrar cada uno, así como un esquema de las relaciones entre sí. Por último, en el apartado de conclusiones, se presentan las consideraciones consecuentes para favorecer los procesos formativos de quienes ejercen la docencia universitaria, tales como el respeto a su diversidad de posturas, contrapeso a los excesos de la mercadización y orientación hacia la autonomía formativa. También se mencionan alternativas para gestar cambios a través de prácticas específicas en las aulas, pautas para la estructura organizativa en las universidades y una propuesta para influir en la cultura educativa desde la función social asignada a la universidad.

PAlabras ClaVE: Enseñanza y formación, profesorado de universidad, programa de formación.

\section{Abstract:}

This paper begins by presenting a background section on the term "formation" and proposing the following methodological objective: "To identify relevant elements for university faculty related to non-formal in-service training components, representing those elements using a scheme to show their articulation, all based on the analysis of empirical data". Another separate section is about conceptual referents, which explain how knowledge is supposed to be generated using Grounded Theory bases (Strauss \&amp;Corbin) along with "Articulated Reconstruction" proposed by Zemelman. The methodological section describes how the information was collected, mainly through semi-structured interviews with eight participants and two coordinators, distributed in three rounds over a period of 22 months. A later section presents results outlining the following six Ordering Concepts:

\section{NotAS DE AUTOR}

picoalanis@outlook.com

\section{DECLARACIÓN DE INTERESES}

1 Doctorado en Educación en la Universidad Autónoma del Estado de Morelos, México. Tiene Maestría en Desarrollo Humano de la Universidad Iberoamericana de Puebla, México. Realizó una especialidad como Experto universitario en servicios de información juvenil e información al ciudadano, en la Universidad de Salamanca, España, y su formación inicial fue como Licenciado en Ciencias de la Comunicación, de la Universidad Intercontinental, en la Ciudad de México. Actualmente realiza una estancia posdoctoral como becario del Consejo Nacional de Ciencia y Tecnología (CONACyT, México) en el Instituto de Investigaciones sobre la Universidad y la Educación (IISUE) de la Universidad Nacional Autónoma de México (UNAM) desde agosto 2015 hasta julio de 2017, bajo la responsabilidad de la Dra. Anita Cecilia Hirsch y Adler. Colabora en proyecto de investigación internacional sobre excelencia del profesorado universitario. Ha escrito dos capítulos de libros. El primero se titula "Excelencia y profesores universitarios", en la publicación electrónica coordinada por Douglas Izarra, titulada Experiencias y perspectivas en ética profesional y responsabilidad social universitaria en Iberoamérica (pp. 158-179). Editado en San Cristóbal, Venezuela, por la Universidad Pedagógica Experimental Libertador, en 2016. El segundo en coautoría con Citlali Romero, titulado "Hacia un concepto articulado y tridimensional de agencia para dispositivos en educación”, en una publicación coordinada por M. T. Yurén y C. Mick, titulada Educación y Agencia. Aproximaciones teóricas y análisis de dispositivos (pp. 351-374). Editado en la Ciudad de México por Juan Pablos, en 2013. 
Agency, Marketization, Proletarianization, Introjection, Resistance and Formative Processes. Examples are provided to illustrate each one as well as a scheme of relationships among them. Finally, in the concluding section, consequent considerations are presented in order to promote formative processes for university professors, such as respect for their diversity, counterbalance excess toMarketization and orientation towards formative autonomy. Alternatives to favor positive changes through specific practices in the classroom, guidelines for the organizational structure in universities, and a proposal to influence on the educational culture from the social function assigned to the universities are mentioned.

KEYWORDS: Teaching and training, Training programmes, Higher education teaching personnel.

\section{CONSIDERACIONES PARA LA FORMACIÓN CONTINUA DE PERSONAL DOCENTE UNIVERSITARIO}

¿En qué radica la importancia de las universidades? Básicamente, en que representan un valioso recurso para la construcción de futuros mejores para las sociedades. De acuerdo con la Declaración Mundial sobre la Educación Superior en el Siglo XXI, de la Organización de las Naciones Unidas para la Educación, la Ciencia y la Cultura (UNESCO por sus siglas en inglés):

En los albores del nuevo siglo, se observan una demanda de educación superior sin precedentes, acompañada de una gran diversificación de la misma, y una mayor toma de conciencia de la importancia fundamental que este tipo de educación reviste para el desarrollo sociocultural y económico y para la construcción del futuro, de cara al cual las nuevas generaciones deberán estar preparadas con nuevas competencias y nuevos conocimientos e ideales. (Altbach, Reisberg, y Rumbley, 2009, p. 19)

Esto se debe a que la educación, en general, está revestida por la esperanza en que a través de ella se pueden lograr los cambios necesarios en la estructura social, así como encontrar respuesta a los grandes problemas que aquejan a la sociedad (Galaz, Padilla, y Gil, 2007). Aun cuando este poder de cambio pudiera estar sobrevaluado, no deja de ser una de las principales herramientas con las que contamos para este fin (Mata, 2002).

Ya desde el último tercio del siglo pasado, Bourdieu y Passeron (1996) sostuvieron que el sistema escolar cumple un una función de reproducción social y que es la universidad la que produce el capital cultural que caracteriza las prácticas pedagógicas dominantes.

En este sentido, podría ser de utilidad la distinción que hacen Maturana y Varela (2009) entre réplica, copia y reproducción, pues la primera proviene de un mecanismo productivo distinto a lo replicado, como una máquina haciendo una producción en serie de zapatos. Por su parte, la copia requiere de un modelo, y en el proceso de elaboración perderá ciertas cualidades, como podría ser el caso de una fotocopia. Finalmente, la reproducción parte de una fractura entre unidades de la misma clase, que al separarse conservan su misma estructura, pero "aunque las unidades resultantes de la fractura reproductiva tienen la misma organización que la unidad original y llevan por lo tanto aspectos estructurales semejantes a ella, también tienen aspectos estructurales distintos de ella y entre sí" (p. 41).

Este es el caso de numerosas estructuras vivas de primer orden (células), segundo orden (organismos multicelulares) o tercer orden (grupos sociales), de manera que la dinámica del aula universitaria es una reproducción y a la vez una reproductora de la sociedad, pues cuenta con características que reflejan la estructura de la colectividad de donde proviene; pero, al mismo tiempo, cuenta con la capacidad de modificar algunos de estos aspectos dando lugar a una nueva versión de sí misma, aunque no necesariamente mejor.

Estos nuevos esquemas de funcionamiento social llegan posteriormente a incontables escenarios culturales, políticos, económicos, etc. desde donde eventualmente se vuelven a reproducir o influyen sobre otras nuevas versiones de organización social. Pero para que todo ello pueda ocurrir, es necesario un primer catalizador en el seno mismo del proceso de reproducción, y las profesoras y profesores son quienes tienen mayores posibilidades de influencia sobre ese espacio, pus en eso consiste su trabajo (Walker, 2016).

Mayores presupuestos, instalaciones e infraestructura, actualización de planes de estudio (el currículo), programas sociales con impacto en la responsabilidad social universitaria (RSU), movilidad estudiantil, mayor cantidad de estudiantes, elevar el nivel académico para el ingreso y optimizar políticas de permanencia; 
todo ello puede contribuir con mejores resultados de las universidades con respecto a su misión -o no--. Pero difícilmente se podría pensar en algún ámbito más estratégico que el de la docencia, lo que a su vez nos remite a su preparación. De esta manera, la formación de docentes en las universidades es un nodo crítico en todo este potencial proceso de transformación social. Esta sería la premisa inicial para esta investigación. Se parte, entonces, de la importancia de los procesos formativos de quienes ejercen la docencia en las instituciones de enseñanza superior (IES).

Por otra parte, si la educación superior tiene una función social preponderante, una misión o razón de ser, parece lógico suponer que la formación para sus docentes también tendría que estar orientada en ese mismo sentido. Al respecto, la UNESCO, en su Declaración Mundial sobre la Educación Superior, se refiere a las misiones fundamentales de educar, formar, investigar y contribuir al mejoramiento de la sociedad. Y añade:

La educación superior está desempeñando funciones sin precedentes en la sociedad actual, como componente esencial del desarrollo cultural, social, económico y político, y como elemento clave del fortalecimiento de las capacidades endógenas, la consolidación de los derechos humanos, el desarrollo sostenible, la democracia y la paz, en un marco de justicia. La educación superior ha de velar por que prevalezcan los valores e ideales de la cultura de paz. (UNESCO, 1998, p. 2)

Pero esta relación entre la finalidad de la educación superior y las orientaciones para la formación de sus docentes no es unívoca, pues como señala Villaseñor (2004), el objeto de la formación universitaria en sus orígenes tenía dos componentes: cultivo del conocimiento y servicio a la sociedad; mas, con el paso del tiempo, se vuelve necesaria su reinterpretación a la luz de nuevos contextos, lo que da origen a posturas cualitativamente distintas. Entonces, la formación de docentes en universidades tampoco tiene una sola orientación claramente definida, pues está sujeta a distintas interpretaciones de las necesidades sociales.

Complejizando el panorama, la educación superior a nivel mundial ha crecido hasta el grado de que la UNESCO reconoce el hacer frente a su masificación como uno de los principales retos para el tercer milenio (Altbach, Reisberg y Rumbley, 2009), lo que adiciona la necesidad de incorporar rápidamente a las universidades un mayor número de docentes.

Aunado a esto, como señalan Zabalza y Zabalza (2012), el contexto actual conlleva cambios importantes sobre la función del profesorado, que se ha construido sobre supuestos que hoy en día están en crisis. Además, frecuentemente las universidades les contratan sin contar con conocimientos previos especializados sobre docencia (Montes y Suárez, 2016; Salas, 2016).

Por todo ello, este artículo pretende aportar consideraciones para la formación de personal docente universitario a partir de resultados provenientes de una investigación que a su vez dio lugar a una tesis doctoral (Alanís, 2014), de manera que quienes tienen responsabilidades sobre procesos de formación continua para profesorado universitario puedan contar con elementos para orientarlo en aras de mejorar la educación de nivel superior y, con ello, impactar positivamente en su proceso de reproducción social.

Así, en un primer apartado se comienza describiendo los antecedentes académicos para contextualizar la investigación, enfocándose en el término "formación" y algunas de sus acepciones en relación con la docencia universitaria. Se concluye enunciando el objetivo metodológico de la investigación.

Posteriormente, en un segundo apartado, se dan especificaciones sobre los criterios y etapas de la metodología seguida. Ya en un tercer apartado, se recuperan los principales resultados obtenidos en relación con los llamados "dispositivos de formación continua no formal" para docentes de nivel superior. Finalmente, en un último apartado se procura dar mayor espacio a la discusión de implicaciones, recomendaciones y consideraciones emanadas de esta investigación, de manera que quien busque contribuir con la formación de docentes en universidades pueda contar con un referente que le aporte una perspectiva más completa frente a esta ardua, pero imprescindible labor de amplias repercusiones. 


\section{ANTECEDENTES}

El término "formación" tiene como una de sus características la polisemia, al punto de que casi podría decirse que se trata de un significante vacío. Venegas (2004) realiza una revisión de las acepciones de este término desde las épocas de la Grecia antigua y encuentra que en relación con el ámbito educativo el uso de este es mucho más tardío, remontándose hasta finales del siglo XI. La autora concluye, entre otras cosas, que a lo largo de la historia de su uso vinculado a la educación hay un universo semántico cohesionado predominantemente por la acción con la que ocurre una modificación o un cambio de forma en la persona.

Por su parte Ducoing (2013), al sintetizar las nociones de "formación" que se manejaron en la investigación educativa mexicana entre 2002 y 2011, describe que en la práctica predomina una concepción instrumental hegemónica de este término, pues la formación se expresa generalmente de manera prescriptiva, buscando asignar una forma determinada a la persona, modelándola y controlándola a través de patrones y estándares fijados por alguien diferente a ella misma, mientras que en el plano teórico ha escaseado la profundización en su construcción conceptual.

Es revelador que entre las muchas investigaciones y ponencias relativas al tema, pocas son las que llegan a describir el significado concreto o las características que se asignan al concepto de formación y, cuando esto sí se llega a hacer, se observa una corriente de significado opuesta a la perspectiva hegemónica de la práctica y su concepción instrumental (Ducoing, 2013).

Desde esta segunda acepción, en contraposición con la hegemónica, se señala que es solo la persona quien auténticamente se puede formar a sí misma -si bien esto no excluye la interacción con sus entornos-, pero este proceso formativo de autoconstrucción la lleva a hacerse más autónoma, autodeterminada y responsable. Así lo refiere por ejemplo Cruz (2005), al señalar dos familias de significado cuando se habla de "formación"; una, la de la intervención pedagógica y otra, la de la conciencia que se tiene de sí para decidir. En el mismo sentido, Figueroa (2009) identifica dos modelos formativos correspondientes a la modernidad y a la transmodernidad. El primero de ellos estaría basado en el conocimiento de lo externo, como en el caso de la formación para el trabajo en el modelo de competencias, mientras que el segundo estaría centrado en el conocimiento y cuidado de sí.

De igual manera González (2006) distingue dos concepciones: una es la de la formación instrumental, delimitada por conocimientos y habilidades para el ejercicio laboral; en contraposición a otra formación que califica de humanista, desde donde surge el desarrollo profesional a lo largo de la vida y es una expresión de la personalidad docente. Pero independientemente de los descriptores elegidos, o ya sea que se les etiquete como familias, modelos o concepciones, lo que salta a la vista es la contraposición de dos enfoques dialécticamente opuestos que muestran una continuidad que se prolonga desde la segunda mitad del siglo XX (Alanís y Romero, 2011).

Naturalmente que entre los extremos existen diferentes posturas matizadas, pero de una u otra forma los objetivos de la formación docente parten de un fundamento que implícita o explícitamente da prioridad a alguna de estas dos perspectivas que están vinculadas con una idea sobre el ser humano o la persona, así como las finalidades que se asignan a la sociedad, la educación, la universidad y la actividad docente.

En la presente investigación, el significado que se estará atribuyendo al término "formación” se acerca más a lo que González (2006) refiere como una concepción humanista. Por ello retomaremos a Yurén (2005), quien hace la distinción entre enseñar, capacitar, educar y formar, como funciones de la docencia:

Entre las funciones [de la docencia] están las de enseñar, capacitar, educar y formar. La primera se orienta a favorecer la adquisición de saberes teóricos y procedimentales, la segunda se orienta a contribuir a la adquisición de saberes técnicos, la tercera y la cuarta más que procurar la acumulación o perfección de un cierto tipo de saberes se orientan a desestabilizar el sistema disposicional completo del sujeto, pero mientras que la tarea de educar se orienta a contribuir a que el sujeto se forme para enfrentar los problemas de la vida diaria, la tarea de formar se orienta a contribuir a que el sujeto se forme para enfrentar los problemas del mundo laboral. (Yurén, 2005, p. 31) 
Yurén (2005) acota que la función docente de formar no debe ser entendida de manera literal, pues es cada persona quien se forma a sí misma, por ello, hablar de formación implica facilitar o propiciar que cada cual realice su propia formación.

Ahora bien, en el caso específico de la formación para docentes de nivel superior, la investigación también ha sido escasa. Así lo refieren Santillán, Viloria y Cordero (2013) en los estados del conocimiento más recientes correspondientes a México, donde solo se encontraron 32 trabajos destinados a este tema durante toda la década - todos de universidades públicas-, y de los cuales únicamente tres correspondieron a artículos arbitrados. Las autoras también señalan que en estas investigaciones hubo continuidad con una visión técnico-productivista, que deja de lado el compromiso por la conceptualización de la formación profesional. Por último, reportan investigaciones que señalan que los posgrados no se están traduciendo en mejoras para la docencia y que tampoco los programas institucionales mostraron mejoras significativas para el ejercicio del profesorado.

En síntesis, la formación es un concepto poco trabajado que en la práctica se utiliza desde una perspectiva instrumental y sin promover la autonomía de la persona; esto, a pesar de que quienes desde la academia profundizan en el tema suelen respaldar una perspectiva más humanista. La formación para docentes de las universidades - pese a su importancia estratégica para la transformación social-también ha sido escasamente investigada. Continúa predominando en la práctica una perspectiva instrumental y así no se está logrando llegar a los resultados que se esperarían de ella.

Ahora bien, para referirse a todos los cursos, talleres, foros, conferencias, etc. que realizan las universidades para que sus docentes se formen, un término apropiado para abarcarlos sintéticamente podría ser el de "dispositivos de formación", pues siguiendo a Albero (2010) se estaría haciendo referencia a una disposición de diversos elementos (programa, espacios, materiales, participantes, coordinaciones, personal facilitador, objetivos, etc.) que se ponen en movimiento como un sistema con una finalidad específica de carácter formativo.

Sin embargo, por su amplitud, esta descripción incluiría también los cursos de licenciatura y posgrados, de manera que se les tendría que agregar otros calificativos en caso de requerir ser más específicos. Así, en concordancia con la UNESCO (Delors et al, 1997), se puede distinguir que la formación de docentes puede ser inicial o continua. La primera se refiere a la preparación previa al ejercicio de la profesión, por lo que ahí entrarían los cursos de licenciatura (los que se asume que ya fueron cumplimentados por quienes imparten clases en universidades). Pero, una vez que ya se está ejerciendo la profesión, resulta pertinente referirse a dispositivos de formación continua.

Por otra parte, la formación continua puede contar con reconocimientos oficiales de grado (maestría o doctorado, por ejemplo), en cuyo caso es además calificada como "formal", mientras que de no contar con dicho aval es considerada "no formal" (Yurén, 2005). De esta manera, la delimitación del tema de la investigación realizada corresponde a "dispositivos de formación continua no formal” destinados a docentes de universidades.

Con respecto a este tema, se consideró que podría obtenerse una mayor riqueza en la información recopilada, si se profundizaba en él partiendo desde la perspectiva de quienes ejercen la docencia. Identificar cuál era su postura con respecto a este tipo de dispositivos, si se percibía que su finalidad estaba en línea con el sentido atribuido a la universidad y al propio ejercicio en las aulas, si estaban favoreciendo procesos auténticamente formativos y bajo qué condiciones esto se promovía o se obstaculizaba. Con estas interrogantes se conformaron preguntas de investigación, evidenciando la necesidad de asumir una perspectiva predominantemente cualitativa.

Cabe señalar que, en su momento, el objetivo de la investigación se enfocó específicamente en circunstancias propias de instituciones de educación superior privadas (que abreviamos como IESPRI, siguiendo a Morales, 2013), pero posteriormente se identificó que el grupo de docentes que se entrevistaron contaban con experiencias de este tipo de dispositivos también en universidades públicas, por lo que 
aportaron información complementaria, por lo que ahora el objetivo se puede sintetizar en nuevos términos, acotados también por las posibilidades de extensión en este artículo:

Identificar elementos relevantes para docentes de universidad en relación con dispositivos de formación continua no formal, representándolos a través de un esquema que muestre su articulación con base en el análisis de datos empíricos.

\section{ReFERENTES CONCEPTUALES}

La presente investigación se realizó de manera generativa. De acuerdo con Goetz y LeCompte (1988, p. 30): "la investigación generativa se centra en el descubrimiento de constructos y proposiciones a partir de una o más bases de datos o fuentes de evidencia". Por ello se procedió de manera inductiva desde las expresiones de las personas entrevistadas, pues fue a partir de ellas que generamos categorías y subcategorías, utilizando criterios de teoría fundamentada (Campo y Labarca, 2009; Meccia, 2007; Strauss y Corbin, 2002). Asimismo, se analizaron las relaciones entre estas categorías siguiendo la propuesta de Zemelman (1987) para una "reconstrucción articulada" con "conceptos ordenadores". Finalmente las consideraciones derivadas del análisis se hicieron con una perspectiva "en caso" (Bertely, 1994). A continuación describimos brevemente los supuestos teóricos que aprovechamos desde estas referencias.

\section{La teoría fundamentada}

La teoría fundamentada es un método inductivo de carácter cualitativo en el que la persona que realiza una investigación genera teoría a partir de datos empíricos recogidos de manera sistemática. Recolección, análisis y teorización son facetas que están estrechamente vinculadas y no suelen buscar la comprobación de una teoría ya existente, sino desarrollarla primordialmente con fundamento en los datos recogidos (Strauss y Corbin, 2002).

La categorización se realiza a través de tres tipos de codificación: abierta, axial y selectiva. La abierta consiste en realizar una conceptualización preliminar derivada de un primer acercamiento a los datos recogidos. Conforme se avanza en ella, los conceptos se agrupan en categorías que se manifiestan con términos explicativos más amplios y abstractos.

En un segundo momento se realiza la codificación axial, en la que se comienzan a identificar relaciones entre las categorías, dando lugar a ejes temáticos de sentido que eventualmente modifican las categorías originales, frecuentemente apoyándose en diagramas simples (Campo y Labarca, 2009). Posteriormente, la codificación selectiva consiste en una depuración y síntesis de las categorías, que jerarquizan y ponderan su relevancia.

En todo el proceso es menester que las codificaciones se realicen paralelamente al trabajo de campo, y este concluye idealmente cuando se hayan saturado las categorías, es decir, cuando los nuevos contactos con el campo ya no estén aportando nada nuevo a las codificaciones. También con este criterio se seleccionan las fuentes de información en campo, buscando que puedan hacer nuevas aportaciones a las categorías. A este procedimiento se le denomina "muestreo teórico" (Meccia, 2007; Strauss y Corbin, 2002).

\section{La reconstrucción articulada}

En la investigación que nos atañe, la teoría fundamentada estuvo supeditada a los criterios metodológicos propuestos por Zemelman (1987), quien parte de que la realidad es "procesable y articulada" (p. 33) gracias a las teorías y los conceptos. Sin embargo, cada teoría surge de contextos específicos espaciotemporales que no necesariamente se ajustan a otros escenarios, lo que constituye un "condicionamiento teórico". 
Del mismo modo, quien investiga está bajo la influencia de referentes que apuntan hacia horizontes ideales, lo que le genera en un "condicionamiento ideológico". Finalmente, el transcurso de los acontecimientos provoca, en quien observa, cierta percepción de que la realidad se comporta de manera constante, lo que sustentaría la vigencia del conocimiento anterior, pero esto no siempre es necesariamente así. A esto se le denomina "condicionamiento experiencial".

Estos tres tipos de condicionamientos (teórico, ideológico y experiencial) obnubilan la lectura de la realidad y no pueden ser erradicados, pero sí se pueden identificar y controlar. Para Zemelman (1987) esta es la función de la problematización, y se consigue a través de lo que él llama "reconstrucción articulada".

El condicionamiento teórico se controla procediendo de manera similar a la teoría fundamentada, construyendo teoría inductivamente a partir de los datos provenientes de la realidad contextual. Con los datos se proponen conceptos de alcance transdisciplinar capaces de entrar en relación (articularse) con otros conceptos provenientes de aproximaciones teóricas diversas (filosofía, pedagogía, psicología, economía, sociología, etc.). Conforme avanza la investigación, los conceptos propuestos se modifican y adquieren características cada vez más precisas y jerarquizadas en función de su capacidad de articulación. Estos son los llamados “conceptos ordenadores" (Zemelman, 1987).

La reconstrucción articulada tiene la finalidad específica de que la construcción de conocimientos "sirva de base a un sujeto social para definir alternativas de acciones posibles" (Zemelman, 1987, p. 57). Esta es la razón por la que se eligió subordinar la teoría fundamentada a la reconstrucción articulada, puesto que se está contemplando la finalidad de proponer consideraciones que favorezcan procesos formativos. De acuerdo con el autor, esta es la clave para el control de los condicionamientos ideológicos, pues permite "cambiar el enfoque de lo deseable, por el de lo posible" (Zemelman, 1987, p. 56), lo que probablemente no sucedería de ajustarse exclusivamente el referente de la teoría fundamentada, en tanto que su finalidad se enfoca primordialmente en la construcción de teoría.

Para el control del condicionamiento experiencial, Zemelman (1987) propone "comparar el contenido informativo de la propuesta con la información que cotidianamente maneja la población, con el propósito de determinar las posibilidades de socialización de los conceptos ordenadores, y/o de enriquecimiento de los mismos" (p. 55). Esto se logra manteniendo un constante contacto con el campo y sus actores a lo largo de todo el proceso analítico (nuevamente de manera similar a lo que propone la teoría fundamentada), que pone a prueba con los sujetos la inteligibilidad y capacidad de articulación de los conceptos ordenadores.

De esta manera, se integraron los supuestos de la reconstrucción articulada con los de la teoría fundamentada, lo que en este caso significó utilizar la codificación abierta para identificar los distintos niveles de realidad o de aproximación teórica presentes en las expresiones de las personas entrevistadas. Con la codificación axial se clasificaron los procesos relacionados con el espacio de realidad investigado, y con la codificación selectiva se distinguieron las características con que se describirían los nuevos conceptos ordenadores.

\section{Estudio en caso}

En cuanto a la construcción de teoría como conocimiento científico, López-Calva (2009b) señala que esta "se ocupa de buscar intelecciones de carácter universal, no solamente aplicables a un caso concreto, sino a todos los casos del mismo tipo" (p. 208). Por ello se optó por apoyarse en el análisis "en” casos, y no "de" casos. La diferencia no es meramente semántica, pues de acuerdo con Bertely, lo genérico se expresa "en" cada caso, ya que "no se trata de estudiar «una totalidad» a partir «de» los casos, sino «en» casos que están determinados, en alguna medida, por la «totalidad»" (Bertely, 1994, p. 32). Esta distinción es de utilidad si se considera que hay una profusa variedad de tipos de estudio de caso (Hernández, Fernández, y Baptista, 2010; López, 2013; Neiman y Quaranta, 2006; Stake, 1999, entre otros) y para la presente investigación importa hacer énfasis en la generación a partir de identificar rasgos de totalidad en los casos particulares. 
De esta manera, aunque cada persona es única e irrepetible, se encuentra en circunstancias estructurales que de hecho ocurren y, por ello, eventualmente podrían verificarse en otras personas. No se busca lograr una representatividad estadística de la realidad, sino aportar elementos para la comprensión de múltiples realidades similares entre sí. La generalización se aplica, entonces, sobre la interacción de los elementos estructurales y no sobre un caso en particular. La búsqueda de estos elementos estructurales fue un criterio que también guio la selección de expresiones de los sujetos entrevistados para la elaboración de los conceptos ordenadores.

\section{La vía metódica}

Giddens (2006) señala que en ciencias sociales no hay lugar para leyes universales, pues la conducta humana es impactada por el saber que se genera sobre ella, de manera que el papel de las ciencias sociales no consiste solo en llegar a generalizaciones, sino en aportar medios conceptuales para explicar una realidad social en la que participan actores que son susceptibles de adoptar o ser influidos por dicha explicación. Este es también el caso de esta investigación, que al ser explicativa contempla la construcción de categorías conceptuales para comprender lo que sucede en torno a la formación de docentes de nivel superior y con ello obtener consideraciones tanto pertinentes como relevantes al respecto.

Por ello, si se entiende la formación desde una perspectiva como la que ya se ha descrito, se puede señalar, junto con Yurén, Araújo y García (2003), esta misma no es medible ni se puede traducir en una calificación, lo que no impide que se le pueda investigar a partir de referentes empíricos. De esta manera, la elección de una postura teórico-filosófica sobre la formación también impacta en las decisiones de carácter metodológico.

En esta investigación se mencionan cuatro aspectos relevantes, en este sentido; el primero corresponde a las características de la muestra (las personas entrevistadas), el segundo a la determinación de observables, el tercero a los instrumentos de recolección y soporte de datos y, como cuarto aspecto, se describe la manera en que los procedimientos de recolección se fueron entrelazando con el análisis y desarrollo de los conceptos ordenadores.

\section{La muestra}

Se conformó una selección de actores para las entrevistas a profundidad a través de un muestreo teórico (Strauss y Corbin, 2002), diseñado para reflejar una diversidad de perspectivas sobre el tema y, a su vez, aportar condiciones propicias para la saturación de categorías conceptuales. Los detalles se presentan en la Tabla 1:

TABLA 1

Conformación de la muestra

\begin{tabular}{lllllllllll}
\hline Seudónimo & Lob & Aco & Pac & Cam & Pep & Sim & Ire & Jor & Fan & Cie \\
\hline Sexo & Masc. & Fem. & Masc. & Fem. & Masc. & Fem. & Fem. & Masc. & Masc. & Fem. \\
Edad & $60+$ & $39-$ & $60+$ & $60+$ & 50 s & 50 s & $40 \mathrm{~s}$ & $40 \mathrm{~s}$ & $39-$ & $39-$ \\
Origen & Lic. & Lic. & Ing. & Lic. & Lic. & Lic. & Ing. & Lic. & Ing. & Ing. \\
Grado & Lic. & Lic. & Mtr. & Doc. & Mtr. & Doc. & Mtr. & Mtr. & Mtr. & Mtr. \\
Privadas & 1 & 2 & 3 & 2 & 4 & 9 & 3 & 2 & 4 & 1 \\
Públicas & 1 & 0 & 3 & 0 & 2 & 7 & 1 & 0 & 0 & 3 \\
Contrato & TC & TC & PA & TC & TC & PA & PA & PA & PA & TC \\
\hline
\end{tabular}


Nota. Las filas de "Privadas" y "Públicas" corresponden a la cantidad de universidades en que se han impartido clases, de acuerdo con su tipo de financiamiento. La fila de "Contrato" indica si el contrato era por tiempo completo (TC) o como profesor/a de asignatura (PA).

\section{Los observables}

La investigación contó con diversos tipos de observables, como los objetos materiales y documentos que las instituciones ofrecieron sobre sus dispositivos (recolectados de manera impresa o digital), o las actividades al interior (observación participante). Sin embargo, estos elementos sirvieron primordialmente para contextualizar a otro tipo de observables que fueron los que finalmente aportaron mayor riqueza para la construcción de las categorías conceptuales: las unidades discursivas. Desde ellas se seleccionaron más de 400 fragmentos con expresiones representativas de las lecturas que los propios actores tenían sobre su realidad.

\section{Los instrumentos de recolección y soporte de datos}

El instrumento más utilizado para esta finalidad fue la entrevista semiestructurada (Hernández, Fernández, y Baptista, 2010). Cada una fue grabada en audio y eventualmente también en video, para ser todas procesadas con un software de tipo CAQDAS (Computer-assisted qualitative data analysis software) llamado Sonal, desarrollado por el sociólogo francés Alex Alber, en 2009, y del que se puede disponer gratuitamente en línea (Alber, 2010). Se entrevistó a cada persona en tres ocasiones a lo largo de 22 meses.

\section{El proceso analítico}

En la primera ronda de entrevistas se indagó acerca de las trayectorias y experiencias formativas. Con ello se elaboraron las primeras categorizaciones y a partir de ahí se desarrolló el guion semiestructurado de la segunda ronda, donde se cuestionó a las personas entrevistadas acerca del papel de la universidad, de su propia labor como docentes, sobre cómo creen que se les percibe, cuáles son los principales problemas a los que se enfrentan (en la docencia), cuál consideran que es su profesión, cómo es su relación con estudiantes, cómo son tratados o tratadas por las IES, para qué creen que les sirven los cursos de formación que les ofrecen, qué principio genérico de acción sugerirían a alguien que va a internarse en la docencia, qué cambios han percibido en su persona a lo largo de su trayectoria como docentes, entre otras preguntas, así como datos más específicos para elaborar una ficha técnica de cada quien.

Con la codificación axial y selectiva de toda esa información se refinaron las categorías y se observó su saturación. Aun así, se llevó a cabo una tercera ronda de entrevistas en la que se validaron las principales interpretaciones y posturas de cada participante, y se cubrieron algunos huecos eventuales de información detectados en las rondas anteriores. Posteriormente se procedió a la redacción de resultados y a la elaboración de un esquema gráfico, que en conjunto se reseñan en el siguiente apartado.

\section{Resultados}

El rasgo característico que se encontró en la generalidad de las personas entrevistadas fue su diversidad de posturas, la que no estuvo relacionada con su género, formación inicial ni con el hecho de que sus contratos fueran de tiempo completo o por asignatura.

No se observó lo mismo en relación con su edad o los años de ejercicio de la docencia, lo cual eventualmente podría vincularse con una perspectiva más crítica sobre las IES así como con una visión más positiva de la 
universidad pública que de la privada, pero estos indicios por ahora son solo un incentivo para investigar más a fondo sobre esas relaciones posteriormente.

\section{Los conceptos ordenadores}

Como resultado del análisis, se identificaron seis categorías principales, correspondientes a igual número de conceptos ordenadores en interacción. Estos fueron: agencia, mercadización, proletarización, resistencia, introyección, y procesos formativos. A continuación se describe, de manera sintética, lo que cada uno de ellos abarca.

Agencia: se refiere al ejercicio de la capacidad para operar cambios en un contexto específico. Surgió como una categoría recurrente tanto para reflejar gran parte de lo que cada enseñante espera provocar en sus estudiantes, así como lo que algunos cursos de las universidades pretenden lograr con sus docentes. Este es un ejemplo tomado de un fragmento de una entrevista con la profesora de seudónimo "Irene":

[>Investig.]: ¿Qué es lo que idealmente debería poder hacer un alumno con lo que le enseñan en la universidad?

[>Irene]: Pues algo en su vida. Yo creo que lo que tienen que poder hacer es aplicarlo, o sea aplicarlo en resolver problemas de la vida diaria, aplicarlo en resolver situaciones cotidianas, y que sean herramientas que cuando ellos menos se den cuenta, los estén utilizando.

Este otro ejemplo corresponde al entrevistado de seudónimo "Lobo", un coordinador de cursos con muchos años de experiencia:

[>Lobo]: Si nosotros estamos preocupados en promover simplemente conocimientos, como a mí me educaron, y no generamos las competencias que le exige la vida profesional en las diferentes áreas, estamos cometiendo un error de estancamiento. De ahí pues, que la capacitación juega un papel importante, porque si no capacitamos a los maestros en estos temas y en esta visión que deben de tener en pleno siglo XXI, por lo menos estamos haciendo válido esa expresión que enseñamos con contenidos del siglo XIX a estudiantes del siglo XX y en una sociedad de exigencias del siglo XXI y no estamos completando ese proceso.

La agencia, adquirida a través de los cursos para docentes o las clases a estudiantes, se vincula estrechamente con la función que se asigna a la universidad, pero en ocasiones se ve influida por una lógica que permea en las IES a nivel global: la mercadización.

El término es retomado de Brunner (2006), con la diferencia de que no nos referimos únicamente a los nuevos modos de financiar la educación superior, sino a toda una lógica aplicada a un sinnúmero de procesos para hacer eficientes procesos que abarquen indicadores de productividad, que consideren entre ellos incluso la relación docente-estudiante. Por esto se eligió la palabra “mercadización” en lugar de "mercantilización”, puesto que en los procesos formativos no siempre se involucra un intercambio real de mercancías, pero sí se les está aplicando una ideología de mercado. Así, el personal docente, al mercadizar su papel, adopta una ideología desde la cual se asume como un proveedor de servicios pedagógicos (Barnett, 2011), procura satisfacer las expectativas de sus clientes, que no son necesariamente sus estudiantes, como lo muestra claramente en el siguiente fragmento el entrevistado de seudónomo "Jorge":

Ellos se sienten que son nuestros clientes, porque te dicen "bueno, tú prestas el servicio, tú enseñas, ese es el servicio, y yo soy tu cliente porque yo le pago a la universidad", que eso es falso, totalmente. Es falso, porque como lo señalaba anteriormente, el cliente de las universidades son los sectores industriales, son las empresas. La materia prima, por así llamarlo, son los alumnos, entonces el beneficio, o sea el esfuerzo que uno hace con los alumnos es para beneficio de las empresas y de México. Y le estamos dando la oportunidad de que sean materia prima de calidad, ¿sí me explico? entonces no son definitivamente, no son el consumidor final, el usuario. Pueden ser en un momento dado el cliente, pero el que lo consume en un momento dado es la empresa, ¿sí me explico? Uno la va transformando, la va desarrollando, la va puliendo, la va... que sea materia prima de calidad, porque es lo interesante, hay materias primas, bueno, malas, son baratas, sí, entonces, el punto es que las empresas, cuando se destaca una universidad, normalmente mandan llamar a los chicos, ¿por qué? porque a la empresa le conviene, va creciendo, entonces ellos sí son nuestros clientes. Imagínate que una empresa te dice, "¿sabes qué" -que ha llegado a suceder en 
ciertos estados y demás- "estamos desarrollando, ejemplo, proyectos de electrónica, necesito que tus alumnos tengan mayores de estos conocimientos y demás" Pues es la oferta y la demanda, muchas veces por eso se cierran también las carreras, no hay demanda, no es necesaria esa área de conocimiento. Entonces realmente nuestros clientes son las... nuestros consumidores son las empresas.

El fragmento anterior es extenso, pero retrata la naturalidad con que la ideología mercadizante se llega a arraigar entre una parte de docentes. "Jorge" en ese momento llagaba a los 40 años, con maestría en educación y más de 10 años de experiencia dando clases. Cursaba un doctorado y era reconocido públicamente por sus buenos resultados. Sus ideas mercadizantes tampoco fueron obstáculo para su propio proceso autoformativo. La diversidad de posturas en la docencia universitaria enriquece la perspectiva para la formación de sus estudiantes, pero los excesos de la mercadización también acarrean consecuencias negativas.

En el caso de los cursos de formación continua, cruzar estos umbrales puede despersonalizar a la gente. Nuevamente se muestra un comentario de "Lobo" como ejemplo:

[...] nosotros tuvimos que establecer procedimientos, al momento en que la universidad se certificó en ISO 9001-2000 y tuvimos que ver la manera más eficiente para que los maestros asistieran a los cursos, es decir, que no fuera una invitación tan abierta, sino que tuviera una orientación hacia las necesidades del profesor, que obviamente son las necesidades de la universidad.

En el fragmento se observa cómo los reclamos de eficiencia sobre las IES se traslapan sobre las necesidades formativas de las personas que ejercen la docencia, de manera que se llega a considerar que son las mismas. Las personas se convierten, entonces, en objetos para la organización, gente que en la práctica es tomada en cuenta principalmente como asalariada y proveedora de un servicio. Ese es el tipo de dinámica que dio pie al concepto ordenador de proletarización, que frecuentemente apareció cercano al de mercadización, aunque no siempre.

El término "proletarización" fue tomado in vivo desde las expresiones en las entrevistas. Corresponde a una forma de relación con un trato predominantemente instrumental sobre las personas, a quienes en la práctica no se contempla como gente adulta con la capacidad de responsabilizarse por la formación de otros seres humanos o incluso por la propia. Así se puede ver en este ejemplo tomado de la entrevistada de seudónimo "Caminante":

A mí me gustaría que en el país al maestro universitario nos trataran bastante mejor, porque los estudios que tiene uno y el esfuerzo que hace uno, etc. Pero económicamente e institucionalmente la sociedad nos mira de una manera pero para las instituciones somos los trabajadores. Le puedes decir los obreros. Entonces, la talacha...

Este tipo de relación laboral también influye en el contexto de los cursos para docentes, como lo refleja nuevamente "Jorge":

Sí he tomado cursos, únicamente he tenido la oportunidad de participar siempre en empresas... ¡en empresas!, en universidades privadas. Eso es importante también señalar. En ciertas universidades te van acreditando horas -vamos a llamarle así- de capacitación, pero son necesarias. Ejemplo, si no cumples con tantas horas al semestre, puedes perder la oportunidad de continuar dando clases, o sea, vamos a llamarle así, es "obligatoria-voluntaria" Porque ellos te dicen "sí, elije el curso, elije tu horario, pero tienes que cubrir tantas horas".

Con la proletarización, las personas son tratadas ya no solamente en función de mejoras en la eficiencia, sino como empleadas, antes que como profesionales. En muchos casos este tipo de dinámicas es el que genera posturas adversas a la implementación de los cursos, y de ello surge el concepto articulado de resistencia, que se refiere a una postura por parte de profesoras y profesores ante los intentos de las IES por formarles, lo que se traduce en estrategias múltiples para oponerse a los dispositivos formativos designados específicamente para la planta docente. Así se puede apreciar en el comentario de este entrevistado:

[>Pepino_di_Caprio]: Que te das cuenta que los maestros son como muy malos alumnos. Cuando los maestros toman un curso, parecen niños, eso es increíble, y de lo mismo que se quejan como maestros, resulta que ellos lo hacen como alumnos. Son vicios que se van repitiendo y es difícil salirse de ahí. 
Las resistencias toman formas muy diversas, desde la oposición directa, pasando por la simulación, y llegando incluso hasta la proactividad para proponer alternativas:

[>Simone]: ¡Ay, ellos sí, ellos sí, ellos sí! Te dicen que si no tomas el curso no te dan clases el semestre que entra, entonces bueno, pues tomas tal vez el más corto, el más rápido, el más indoloro, -porque todos son incoloros-, entonces tratas de cubrir administrativamente sus necesidades.

En contraposición a las resistencias, está la Introyección, término tomado del ámbito de la psicología, que se utiliza en esta investigación para señalar características actitudinales elegidas de manera unilateral por las IES para ser implantadas entre sus docentes, sin propiciar cuestionamientos al respecto, apoyándose en el discurso institucional. No faltaron participantes que coincidieran ampliamente con estas propuestas institucionales e incluso sugirieran ir más allá, como lo señala nuevamente "Jorge" en este comentario:

\begin{abstract}
Sí, porque pasa, ¿eh? Suponiendo hay profesores que dicen de repente "Ya vámonos ¿̇no?" O sea te lo creo de los alumnos, de los chavos, pero ¡cómo un profesor puede decir "ya vámonos"! No está consciente de la labor, o tiene como esa antigua mentalidad de ser el como dicen, "Pobresor", porque no sé, en México se tiene esa idea de los profesores como de que estás ahí, relegado. En lo absoluto, en países industrializados, vamos a decir en países ricos o poquito más inteligentes, les llamo inteligentes porque su capital intelectual lo nutren, normalmente los profesores son gente muy capaces con estrategias, con experiencia, que son también reconocidos en su área, entonces por eso considero que sí, es una necesidad hacer consientes a los profesores de su capacitación, y que sí sea obligada si quieren sustentar ese título. Sí.
\end{abstract}

La postura de la docencia universitaria ante la Introyección, como en el caso de la mercadización, es diversa. Así como hay quienes la integran a su sistema de creencias, también hay quienes la repudian, tanto en la propia persona como hacia sus estudiantes. Esto se observa en el siguiente fragmento de la entrevistada de seudónimo "Simone":

Porque entonces no estamos preparando para la vida. O sea, por un lado el discurso es "educamos de manera integral, un ser humano..." ¿no? y luego resulta que solamente educamos para un espacio laboral, para producción, para calidad, para el éxito, y si no logras todo eso, entonces, qué clase de persona eres; si todo tu ser y tu valía y tu estancia en el planeta tiene que ver con este tipo de cosas, pues entonces eres un ser humano de desecho, o un cuasi-ser-humano.

En las entrevistas también se encontraron numerosas expresiones aportadoras de indicios de auténtica formación, lograda a través de dispositivos formales o informales, con condiciones de respeto a las elecciones personales, que dan lugar al concepto ordenador de "procesos formativos", con dos subcategorías. La primera se refiere a la autoformación, comprendida esta como la toma del mando sobre la propia trayectoria de crecimiento y desarrollo. La segunda se denominó coformación y se relaciona con la implementación de espacios colectivos donde se pudiera aprender a partir de las experiencias de otras personas y junto con ellas.

Se encontró que las personas entrevistadas habían tomado opciones de aprendizaje que iban más allá de las exigencias institucionales, principalmente con la elección de un posgrado, pero también haciendo investigación autodidacta, consultando gente experta o tomando cursos en espacios extrauniversitarios, como lo refiere el entrevistado con el seudónimo de "Paco", que con más de 60 años de edad asiste asiduamente a los dispositivos de otro instituto al que no está adscrito:

[...] me encanta ir a ver otro mundo que no es de ingeniería, el mundo de las humanidades, la investigación de la historia, de antropología... cada semana dan conferencias ahí, y no es un curso formal, pero aprendo mucho.

Ante la diversidad de intereses de los profesores y profesoras, la oferta de sus IES puede pasar de largo inadvertidamente al no representar algo significativo, sin embargo, en ocasiones esto no impide que los procesos autoformativos se abran paso desde una agenda personal de intereses, aun ante dispositivos obligatorios de mala calidad, como señala la entrevistada de seudónimo "Irene":

Por lo menos yo sí siempre aprendo de todos lados, de todos, así me mandes al curso más rarísimo del mundo, siempre aprendo algo. Hasta cómo no darlo mal. Hasta eso. ¿No? dices: "qué malas están las normas, nunca voy a hacer eso". De que aprendes, aprendes, siempre. 
En cuanto a la coformación, nos percatamos de que esta aparece poco en las expresiones de las entrevistas, sin embargo, refleja un enriquecimiento singular de los procesos formativos, aun cuando frecuentemente se le observó vinculada a espacios informales por fuera de la estructura de las IES, como lo deja entrever "Simone" en este comentario:

Yo extraño mucho trabajar en colegio. Con pares, y ahora, incluso con dispares, porque se mete a nivel mundial en otros lugares, convocan a ingenieros, arquitectos, a químicos, a filósofos, a educadores, y todos ahí haciendo un gran collage del conocimiento. A mí me gustaría una posibilidad de transversalidad en el conocimiento. Realmente recrear una sociedad del conocimiento desde una visión de convivencia, porque no es en la coerción y en los horarios estos rígidos donde puede promoverse la creatividad. Creo que es en estos lugares más lúdicos donde puede crearse.

Autoformación y coformación no son subcategorías "químicamente puras", pues a menudo las fronteras entre ellas son borrosas. Sin embargo, esto es hasta cierto punto normal, dado que los conceptos tienen una función explicativa y relacional compleja, más que el delimitar fronteras cognitivas, pues como señalan Strauss y Corbin (2002): "El analista codifica para conseguir explicaciones y para comprender los fenómenos y no los términos tales como condiciones, acciones/interacciones y consecuencias" (p. 141).

Para el caso de la presente investigación, se encontró que los procesos auténticamente formativos (desde la perspectiva humanista, que identifica que es la persona quien se forma a sí misma de manera autónoma) ocurren con naturalidad entre docentes de universidad, mientras que los dispositivos de las IES ocasionalmente les estorban o son resignificados por estas personas para que se ajusten a sus propios intereses formativos. Aun así, el análisis también muestra que hay factores que pueden favorecer u obstaculizar estos procesos, lo cual es algo que abordaremos más específicamente en las conclusiones de este trabajo.

\section{Las articulaciones}

Los seis conceptos ordenadores que acabamos de sintetizar aparecieron de manera recurrente durante el análisis de las entrevistas. La relación entre algunos de ellos es más frecuente que entre otros y las articulaciones se pueden rastrear hasta el interior de los fragmentos. Por ejemplo, en un fragmento de una entrevista con el profesor con el seudónimo "FAN", él comienza refiriéndose a lo que le aportan los cursos (concepto ordenador de procesos formativos), y termina hablando de la necesidad de que sus estudiantes puedan aplicar conceptos (agencia):

[sobre los cursos...] yo creo que te dan un patrón, no un patrón, sino como una guía para poder mejorar tus clases, tu desempeño en clase, involucrar mayores herramientas, para hacerlo más dinámico. El chavo de hoy en día no es tan fácil de llegar y darle una clase de hora y media, tú parado hablándole. Necesitan encontrar la técnica, el balance para que esté entretenido en tu clase, pero no de que "hay, pues sí, vamos a contar chistes", sino de que esté realmente atento a tu clase y la entienda y sepa la aplicación del concepto.

En el fragmento se articula un proceso formativo (identificado por la adquisición de un patrón o guía para mejorar el ejercicio en el mundo laboral), con el ejercicio de la capacidad de agencia, haciendo más dinámicas sus clases, de manera que sus estudiantes entiendan la aplicación de los conceptos (lo que identificamos como una modificación efectiva de un contexto). Así, la relación entre procesos formativos y agencia podría plasmarse como una línea entre dos núcleos, como una representación del análisis de este fragmento.

En la siguiente figura cada concepto ordenador se muestra representado por un círculo de tamaño proporcional a la cantidad de fragmentos discursivos en que fue aludido, mientras que el grosor de las líneas que los vinculan también es proporcional a la cantidad de veces en que dos o más de estos conceptos aparecieron dentro de un mismo fragmento. 


\begin{tabular}{|c|c|c|c|c|c|c|c|c|}
\hline & Variable & Categories & $\begin{array}{l}\text { Physionterapy } \\
\end{array}$ & Taping & 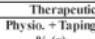 & $\begin{array}{l}\text { Tratalumant } \\
\text { Trping + Physio. }\end{array}$ & Totat & $p$ \\
\hline & Age & Years & 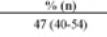 & $\frac{1 \%(1)}{43(33.50)}$ & $\frac{10(1)}{46(3+50)}$ & $\begin{array}{l}\frac{\%(n)}{4(41-57)} \\
47\end{array}$ & $\frac{\text { Iotis }}{47085.51 .5)}$ & 0.49 \\
\hline & sex & ${ }_{\mathrm{M}}^{\mathrm{F}}$ & 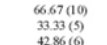 & $\begin{array}{l}8000(12) \\
2000(8) \\
40006\end{array}$ & $\begin{array}{l}7.33(11) \\
2667(4) \\
2.676(4)\end{array}$ & 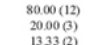 & 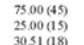 & a.9 \\
\hline \multirow[t]{4}{*}{ aphic Variables } & & ${ }_{3}^{2}$ & 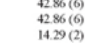 & 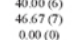 & 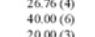 & $\begin{array}{l}1333(8) \\
32330(5)\end{array}$ & 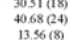 & 0.23 \\
\hline & 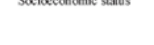 & $\begin{array}{l}\text { Eemenary } \\
\text { Secomatry }\end{array}$ & $\begin{array}{l}0 \\
3333(8) \\
76670\end{array}$ & $\begin{array}{l}1333(2) \\
5333(8)\end{array}$ & $\begin{array}{l}1332(2) \\
2000(3)\end{array}$ & $\begin{array}{l}3333(8) \\
3333(8)\end{array}$ & $\begin{array}{l}1323(9) \\
000024)\end{array}$ & \\
\hline & Edxacation kevel & 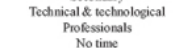 & 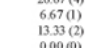 & 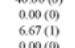 & $\begin{array}{l}13,33(2) \\
0.00(1) \\
0.607\end{array}$ & 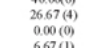 & $\begin{array}{l}1,167(7) \\
3.008)\end{array}$ & 0.09 \\
\hline & Time Dedicated to Work & 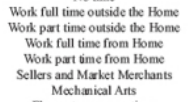 & 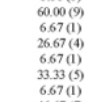 & 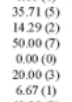 & 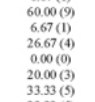 & 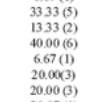 & 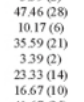 & a.n \\
\hline \multirow[t]{3}{*}{ Occupational variablo } & Ocuppaion & 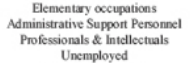 & 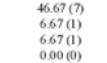 & 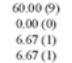 & 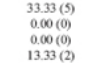 & $\begin{array}{l}2.67(4) \\
26.67(4) \\
0.00(1) \\
6.67(1)\end{array}$ & 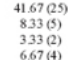 & 0.20 \\
\hline & & 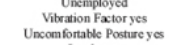 & 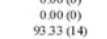 & 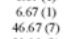 & 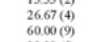 & $\begin{array}{l}3673(1) \\
46.57()\end{array}$ & 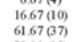 & $\begin{array}{l}0.0 .6 \\
0.02\end{array}$ \\
\hline & Ocupstional Risk Faters & 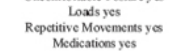 & 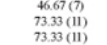 & 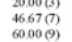 & 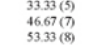 & 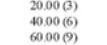 & 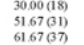 & $\begin{array}{l}0.37 \\
0.26 \\
0.79\end{array}$ \\
\hline \multirow[t]{4}{*}{ Treatments } & Matiations & $\begin{array}{l}\text { NSAIDs } \\
\text { Ansagess ses } \\
\text {. }\end{array}$ & 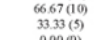 & 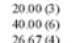 & $\begin{array}{l}4000(9) \\
6.67(1) \\
1330\end{array}$ & $\begin{array}{l}3333(5) \\
20000(8) \\
20670\end{array}$ & 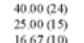 & $\begin{array}{c}a .08 \\
0.17 \\
0.17\end{array}$ \\
\hline & & 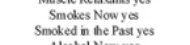 & $\begin{array}{l}6.67010 \\
200003\end{array}$ & 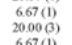 & 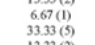 & $\begin{array}{l}0.00(1) \\
13332 \\
1332)\end{array}$ & $\begin{array}{l}5.506) \\
21.67(13)\end{array}$ & $\begin{array}{l}1 \\
0.69\end{array}$ \\
\hline & & 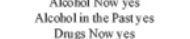 & $\begin{array}{l}30338) \\
00000\end{array}$ & 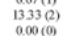 & $\begin{array}{l}3.3385 \\
0.000\end{array}$ & 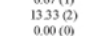 & 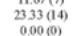 & $\begin{array}{l}0.39 \\
0.39 \\
0.01\end{array}$ \\
\hline & Unheathly Habits & 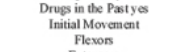 & $\begin{array}{l}0.00(0) \\
60(20.89) \\
3(3 \rightarrow)\end{array}$ & 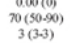 & 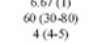 & 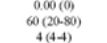 & 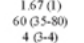 & $\begin{aligned} 1 \\
0.57 \\
<0.01\end{aligned}$ \\
\hline \multirow[t]{5}{*}{ Bechavioral Factors } & & 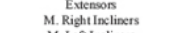 & 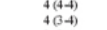 & $\begin{array}{l}4(3-4) \\
3(3-3)\end{array}$ & 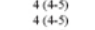 & 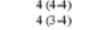 & $\begin{array}{l}+(+4,4) \\
4(3-4)\end{array}$ & $\begin{array}{l}a_{0.03}^{0.01} \\
<0.01\end{array}$ \\
\hline & Initial Muscular Strengegh & 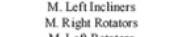 & $\begin{array}{l}3,4 \rightarrow \\
4 \beta \rightarrow 1\end{array}$ & 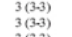 & 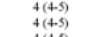 & 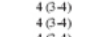 & 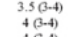 & $\begin{array}{l}<0.01 \\
<<.01 \\
<0.01\end{array}$ \\
\hline & & 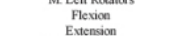 & 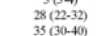 & 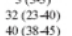 & 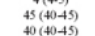 & 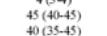 & 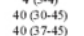 & $\begin{array}{c}<0.01 \\
0.00\end{array}$ \\
\hline & Intitis Join Mobility & 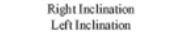 & $\begin{array}{l}33(30-49) \\
33(30.49)\end{array}$ & $\begin{array}{l}3(28-40) \\
30(24+2)\end{array}$ & 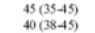 & $\begin{array}{l}40(30-4) \\
45(40-45)\end{array}$ & $\begin{array}{l}\begin{array}{l}39(30-4) \\
40(30-4)\end{array} \\
40\end{array}$ & $\begin{array}{l}0.02 \\
<0.01\end{array}$ \\
\hline & & 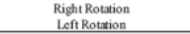 & 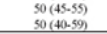 & 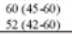 & 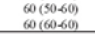 & 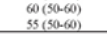 & 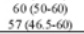 & 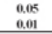 \\
\hline
\end{tabular}

FIGURA 1

Esquema gráfico de articulación de conceptos ordenadores. A: Agencia; R: Resistencia; M:

Mercadización, P: Proletarización, I: Introyección; F: Procesos Formativos. Elaboración propia.

Así, en la figura 1 se puede ver que la agencia fue el concepto ordenador más referido, con 182 fragmentos en los que fue identificada, seguida por la mercadización (141), proletarización (117), resistencia (83), procesos formativos (76), e Introyección (39). Los más relacionados fueron la mercadización con la proletarización (60 interacciones); la mercadización con la agencia (41), y la agencia con los procesos formativos (28), pero estas articulaciones no siempre fueron en sentido positivo, pues en ocasiones se vincularon conceptos a través de una relación negativa. Por ejemplo, la relación positiva entre mercadización y proletarización frecuentemente se vinculó con efectos contraproducentes para la agencia y los procesos formativos.

De la misma manera, la proletarización se vinculó positivamente con la generación de expresiones de resistencia, y esta a su vez favoreció procesos formativos, pero ello no significa que la proletarización beneficie directamente a la formación. Es el clima de resistencia el que se relaciona favorablemente con la formación y, aún más, esto no significa que la formación sea consecuencia directa de la resistencia, sino que es frecuente que ambas coexistan, como se refleja en este comentario de "Caminante": "Bueno, es parte de la naturaleza del ser humano ser reacio a los cambios, y los cursos significa cambios, propuesta de cambios, de cambios de actitud. [...] Me parece que la universidad debería de tal vez incrementar más cursos”.

El análisis de las articulaciones entre los conceptos ordenadores permitió identificar condiciones que favorecieron los procesos formativos, tomando en cuenta características propias del contexto docente en las universidades. Hasta aquí se ha descrito, a grandes rasgos, el tema de esta investigación, antecedentes, objetivo, vía metódica y principales resultados. A continuación se presentan algunas de sus conclusiones estratégicas para ser tomadas en cuenta con respecto a la formación continua del personal docente universitario; ello con la finalidad de aportar orientaciones prácticas sobre las que sea posible reflexionar y eventualmente impactar en políticas o prácticas institucionales.

\section{CONCLUSIONES: IMPLICACIONES Y CONSIDERACIONES}

Al principio de este artículo se señalaba el papel de las universidades como espacios de gestación para el cambio social, así como lo imprescindible que son sus docentes y la formación continua para todo este proceso. Esta 
investigación permite identificar de manera inductiva seis categorías relevantes con respecto al tema, desde la perspectiva de quienes protagonizan estos dispositivos. Desde ahí se derivaron seis conceptos ordenadores con sus articulaciones y a partir de todo ello se hace esta propuesta de consideraciones sobre la formación continua de docentes de universidad, en procura, también, de que puedan ser de apoyo para orientar las estrategias de las IES al respecto.

Para comenzar, habría que señalar la pluralidad de posturas entre docentes de las IES, que difícilmente podría ser evitada. Las personas que imparten clases en universidades son diversas en sus percepciones, apreciaciones y lecturas sobre la realidad que les rodea, y esto incluye cuestiones como el papel que asignan a sus estudiantes, a la universidad, a su propia labor como docentes así como en sus percepciones sobre el entorno nacional e internacional. Pretender allanar sus diferencias atentaría contra los propósitos de la universidad como espacio de formación de nivel superior abierto al mundo, e incluso como institución inmersa en un contexto de globalización. Por el contrario, la formación -entendida desde una perspectiva humanista- se ve favorecida por la diversidad de posturas ideológicas y el diálogo entre ellas. No obstante, hay dispositivos de IES que pretenden homogeneizar los perfiles de sus docentes en torno a un discurso y valores institucionales. Este tipo de introyección puede resultar estéril, además de que cada docente eventualmente aprende a lidiar con las imposiciones a partir de estrategias de resistencia y simulación.

Las IES tienen el derecho (y posiblemente hasta el compromiso moral) de tomar postura frente al entorno, así como con respecto al papel de la universidad, el rol docente y de sus estudiantes; y de hecho en la práctica tampoco puede abstenerse de reflejar esta postura a través de sus estructuras, políticas y acciones. Pero de igual manera, tampoco puede prescindir de la diversidad a la que se ha hecho referencia en la docencia. Por ello, sería idóneo que las instituciones apostaran por mecanismos de diálogo con (y entre) sus docentes, lo que también favorecería sus procesos formativos así como los de sus estudiantes. Desgraciadamente las dinámicas de proletarización ponen a las personas a la defensiva y les sumergen en prácticas de simulación, puesto que los espacios para el diálogo franco también requieren de garantías de respeto y confianza mutua, sin que esto implique un riesgo para la conservación del trabajo.

A pesar de las diferencias entre docentes dentro de una misma institución universitaria, un punto en común encontrado en sus entrevistas (exceptuando curiosamente a quienes coordinan los cursos), es que se ocupan activamente de su propia formación; independientemente de los cursos que las IES les exigen tomar, las personas buscan otros espacios en donde puedan encontrar enriquecimiento, frecuentemente en forma de programas de posgrado, que a veces ni siquiera se toman en cuenta como sustituto de los cursos de formación continua a los que se les coacciona para asistir.

Una de las características contextuales de la educación superior en Latinoamérica y el mundo, es la mercadización, que funciona como una ideología de rasgos sombríos, pero también con algunos luminosos. De acuerdo con Barnett (2011), lograr que su lado negativo no predomine es el principal reto pedagógico de nuestros tiempos. En el caso de los dispositivos de formación continua no formal para docentes, encontramos múltiples manifestaciones de mercadización, presente tanto en la manera de abordar los contenidos, en las estrategias institucionales para convocar participantes para estos dispositivos (a menudo bajo presión para cumplir con indicadores de eficiencia), o también adoptada por profesoras y profesores, cuando desde una lógica mercadizante calculan su costo-beneficio para decidir cómo responder a la oferta formativa de las IES.

Como señala Barnett, la educación superior no puede mantenerse al margen de la mercadización y esto incluye los dispositivos de formación para docentes. En un contexto de globalización y creciente participación del sector privado, la mercadización es un elemento ineludible de la reproducción social que acontece actualmente en la universidad, y esto no solo ocurre en Latinoamérica.

Así, una consideración con respecto a la mercadización consiste en no procurar erradicarla por completo, sino asumirla implementando los contrapesos necesarios para atemperar sus efectos negativos. Una manera muy concreta de hacerlo es a través del discurso institucional acerca del papel de la universidad, pues se pudo observar que hay docentes que adoptan elementos de los discursos institucionales para explicarse su propia 
función dentro de la universidad. Las IES pueden proponer lecturas más acordes con su propio ideario, sin necesidad de atentar contra la pluralidad de perspectivas de sus docentes, pero para ello es necesario procurar que no se perciba un doble lenguaje, o un discurso en contrasentido con las políticas y prácticas desde donde la institución actúa. Esto podría atenderse previniendo la introyección y dando espacio a las voces críticas frente a la mirada institucional.

De esta manera, por ejemplo, es contradictorio que en una IES se mencione que se aspira a formar estudiantes con perspectiva crítica y sentido humanista o social, cuando a sus docentes en la práctica de los dispositivos, que tendrían que favorecer procesos de formación, se les trata como a burócratas en la pasividad e incapaces de elegir o pronunciarse sobre sus propias opciones formativas.

El desarrollo de agencia requiere de favorecer la formación a través de la paulatina adquisición de autonomía por parte de la persona, para que esta pueda entrar en dinámicas autoformativas y coformativas, sin embargo, esa no suele ser la intención reflejada en los dispositivos destinados a docentes de universidad. No se trata de modificar contenidos curriculares, sino de abordarlos desde otra perspectiva en la que la persona pueda tomar las riendas de su propio proceso formativo.

\section{Alternativas para gestar cambios}

Para la siguiente parte de las conclusiones se abarcarán los tres niveles propuestos por López-Calva (2009a) para propiciar transformaciones educativas: a) prácticas concretas, b) estructura organizativa, y c) cultura educativa. Al adentrarse en estos ámbitos, la investigación amplía su relevancia para su posible aplicación en el campo de la formación continua de docentes en el nivel superior.

Sobre los cambios en las prácticas concretas que atañen a quienes protagonizaron la investigación (personas que ejercen la docencia universitaria), se obvia el que se hagan cargo de su propio proceso formativo porque esto es algo que, por lo que se observó, la mayoría ya lo hace. En cambio, les instamos a que presten atención a la manera en que funcionan las relaciones sociales dentro de los dispositivos formativos en que participan y que tomen conciencia de cómo estas pueden reproducirse en otros espacios sociales, comenzando por sus propias aulas, gestando pequeñas pero significativas modificaciones sociales. Podrán elegir, entonces, las que les parezcan más necesarias de acuerdo con el contexto local, nacional e internacional, experimentando constantemente con diferentes esquemas organizativos y tomando en cuenta el desarrollo de agencia así como de procesos auténticamente formativos.

En el mismo sentido, es necesario prestar atención para evitar dinámicas de proletarización e introyección activas ya desde el interior de los salones de clase a través de las relaciones entre docentes y estudiantes.

Finalmente, como recomendación para los profesores y profesoras que decidan optar por la resistencia, es deseable procurar que esta no sea reactiva y aislada, sino ponderada conscientemente y, de ser posible, acompañada por pares a fin de que no resulte desgastante y eventualmente pueda dar paso a modificaciones efectivas. Esta sería una recomendación prioritaria para docentes de nivel superior en general, y no solo para quienes son resistentes: no quedarse en aislamiento; acompañarse, compartir las experiencias, logros y dificultades; y no solo para facilitar su coformación, sino por otros beneficios secundarios en términos de agencia y reproducción social.

Para quienes coordinan cursos y eventualmente no pueden evadir lineamientos institucionales con respecto a las temáticas de los dispositivos que les toca implementar, es notorio que en ocasiones sí pueden influir para que la participación no sea solo por obligación. Dar mayor seguimiento a las personas en concreto permitirá identificar lo que favorezca más su formación, así como promocionar a través de ellas una reproducción social más funcional. Igualmente es importante que no descuiden su propia formación.

Entre las personas entrevistadas, quienes coordinaban los cursos fueron las que menos se involucraban en su propia formación, pues a diferencia de las demás, no mencionaron asistir a ningún dispositivo como participantes por su propio interés, ni tenían ningún posgrado, o mostraban intenciones de realizarlo en el 
corto o mediano plazo. El atender su propia formación les permitirá empatizar mejor con docentes a quienes dirigen sus cursos, así como comprender mejor sus resistencias y necesidades. Eventualmente, también podrían tener mayores posibilidades para incidir en modificaciones a las estructuras de las IES concernientes a los dispositivos de formación continua.

Para las universidades, las alternativas viables y factibles en relación con los dispositivos formativos son relativamente sencillas, dado que las acreditaciones suelen ser ambiguas en cuanto a la documentación de acciones por la calidad de la docencia. Esto abre las puertas para dejar de implementar cursos remediales en los que se obliga a participar a profesoras y profesores, generando resistencias innecesarias, así como mayores costos a partir de dispositivos de poca utilidad y a veces también de dudosa calidad.

En cambio, las IES podrían favorecer el que sus docentes participaran en dispositivos elegidos de manera autoformativa, dentro o fuera de la estructura institucional, acreditando cierta cantidad de horas que respondan a sus genuinos intereses y necesidades, e incluso, eventualmente, apoyándoles en proyectos autoformativos y coformativos de diversas maneras, generando, así, además, un mayor compromiso con la institución. De la misma manera, sería conveniente que se tomara en cuenta que hay docentes que ya están participando en dispositivos de formación continua formal, como son cursos de especialidad, maestría o doctorado, o participando en proyectos de investigación. Esto tendría que valerles como evidencia de actualización.

También sería factible propiciar espacios voluntarios de coformación para promover la reflexión sobre la propia práctica docente, en los que puedan encontrarse personas de distintas edades y representando a distintas disciplinas, dado que la investigación da cuenta del provecho formativo que se obtiene de tales dispositivos. La universidad bien podría apoyarles con recursos de infraestructura dejando que la organización del dispositivo corriera por cuenta de sus docentes, aunque sin dejar de supervisarles y darles seguimiento. Los resultados de estas experiencias podrían documentarse y, a partir de ellas, realizar nuevas aportaciones a la investigación educativa (Ruffinelli, 2017), así como reproducir modelos formativos para otros niveles escolares.

Es preferible que todos estos esfuerzos sean de alguna manera remunerados para el personal docente y que no se les haga coerción para que participen en este tipo de proyectos, lo que supondría un fracaso en términos de formación. En todo caso, si no hubiera recursos financieros disponibles, la institución podría ofrecer su respaldo para conseguir apoyo de otras instancias, o al menos dar un sustento más formal al reconocimiento de participantes. Estas alternativas son viables y podrían ser efectivas, pues representan una mejor opción que el obligar a sus docentes a asistir a cursos ideados por alguien que unilateralmente dice conocer sus necesidades, pero que en realidad solo tiene interés en mejorar sus indicadores.

Ya a escala de gobiernos nacionales, hasta donde se pudo observar dentro del alcance de esta investigación, el panorama de la educación superior se ha estudiado poco en términos de mercadización. Se puede incidir en las estructuras de la educación superior para poner algunos contrapesos a la tendencia mercadizante que irremediablemente les influye, así como prevenir de alguna manera la proletarización y la introyección. Los gobiernos nacionales y sus instancias intermedias pueden presionar a las universidades para que no se guíen exclusivamente por su propia lógica de mercadización y, en todo caso, incorporen a esta los indicadores o requerimientos estructurales necesarios para prevenir -o al menos dificultar- específicamente la proletarización y la introyección.

Finalmente, de las transformaciones necesarias, efectivas y viables que se podrían vislumbrar en torno al ámbito de la cultura educativa, la más significativa se refiere a la finalidad de los estudios universitarios, en el sentido de que su meta principal no necesariamente tendría que ser el aseguramiento de la subsistencia, concepción muy difundida que se observa aún arraigada en el imaginario docente. El éxito económico puede ser favorecido por una formación universitaria, pero no tendría por qué ser su principal finalidad, la cual, de acuerdo con lo observado en esta investigación, podría describirse como el apuntalamiento de un proyecto personal de vida a partir de decisiones propias, en favor del beneficio social y del entorno, con base en el 
acceso, producción y difusión del conocimiento; que contribuye, así, a la aportación de soluciones para los grandes y pequeños problemas a los que se enfrenta la humanidad, e influye en la transformación del sistema educativo, así como de la sociedad en su conjunto.

\section{REFERENCIAS}

Alanís, J. F. (2014). Relación entre la mercadización, la agencia y la proletarización del docente. Estudio en casos de formación continua no formal para profesores de universidades privadas [Tesis Doctoral en Educación]. Cuernavaca: Instituto de Ciencias de la Educación - Universidad Autónoma del Estado de Morelos.

Alanís, J. F., y Romero, C. (2011). Seguimiento y evolución en las nociones de formación con eco en el panorama educativo mexicano a inicios del siglo XXI. En Consejo Mexicano de Investigación Educativa. Memoria Electrónica (CD-ROM) del XI Congreso Nacional de Investigación Educativa. México: COMIE.

Alber, A. (7 de julio de 2010). Voir le son: réflexions sur le traitement des entretiens enregistrés dans le logiciel Sonal [Ver el sonido: reflexiones sobre el tratamiento de entrevistas registradas con el programa Sonal]. Socio-logos. Revue de l'association française de sociologie, 5. Recuperado de https://socio-logos.revues.org/2482

Albero, B. (2010). La formation en tant que dispositif : du terme au concept [La formación como dispositivo: del término al concepto]. En B. Charlier y F. Henri, La technologie de l'éducation: recherches, pratiques et perspectives [La tecnología de la educación: Investigaciones, prácticas y perspectivas] (pp. 47-59). París, Francia: Presses Universitaires de France.

Altbach, P. G., Reisberg, L., y Rumbley, L. E. (2009). Tras la pista de una revolución académica: Informe sobre las tendencias actuales. Resumen para la Conferencia Mundial sobre la Educación Superior organizada por la UNESCO en 2009. París, Francia: UNESCO.

Barnett, R. (2011). The marketised University: defending the indefensible [La universidad mercadizada: defendiendo lo indefendible]. En M. Molesworth, R. Scullion y E. Nixon, The marketisation of higher education and the student as consumer [La mercadización de la educación superior y el estudiante como consumidor] (pp. 39-51). Abingdon, UK: Routledge.

Bertely, M. (1994). Retos metodologicos en etnografia de la educacion. Coleccion pedagogica universitaria, 25-26, 31-46.

Bordieu, P. y Passeron, J. C. (1996). La reproducción. Elementos para una teoría del sistema de enseñanza (2a ed.). México: Fontamara.

Brunner, J. J. (2006). Mercados universitarios: Ideas, instrumentaciones y seis tesis en conclusión. Santiago de Chile: FONDECYT

Campo, M. y Labarca, C. (2009). La teoría fundamentada en el estudio empírico de las representaciones sociales: Un caso sobre el rol del orientador docente. Opción, 25(60), 41-54.

Cruz, O. P. (2005). La formación docente. Una mirada genealógica del concepto. En Consejo Mexicano de Investigación Educativa. Memoria Electrónica (CD-ROM) del VIII Congreso Nacional de Investigación Educativa. Hermosillo, México: COMIE.

Delors, J., Al Mufti, I., Amagi, I., Carneiro, R., Chung, F., Geremek, B., ... Nanzhao, Z. (1997). La educación encierra un tesoro. Informe a la UNESCO de la Comisión Internacional sobre la Educación para el siglo xxi, presidida por Jacques Delors. México: Organización de las Naciones Unidas para la Educación, la Ciencia y la Cultura.

Ducoing, P. (2013). Nociones de formación. En P. Ducoing y B. Fortoul (Eds.), Procesos de formación (volumen I 2002-2011, pp. 47-106). México: ANUIES-COMIE.

Figueroa, L. M. (2009). La formación de docentes. Entre la dualidad del saber y el afecto. En Consejo Mexicano de Investigación Educativa. Memoria Electrónica (CD-ROM) del X Congreso Nacional de Investigación Educativa. Veracruz, México: COMIE.

Galaz, J. F., Padilla, L., y Gil, M. (2007). The Increasing Expectation of Relevance for Higher Education and the Academic Profession: Some Reflections on the Case of Mexico [El incremento de expectativa sobre la relevancia para la educación superior y la profesión académica: Algunas reflexiones en el caso de México]. En M. Kogan, 
y U. Teilcher, Key challenges to the academic profession [Retos clave para la profesión académica] (pp. 49-62). Kassel, Alemania: UNESCO Forum on Higher Education Research and Knowledge / International Centre for Higher Education Research Kassel.

Giddens, A. (2006). La constitución de la sociedad. Bases para la teoría de la estructuración. Buenos Aires, Argentina: Amorrortu.

Goetz, J. P., y LeCompte, M. D. (1988). Etnografía y diseño cualitativo en investigación educativa. Madrid, España: Morata.

González, V. (2006). El diario como instrumento de diagnóstico y estimulación del desarrollo profesional del profesorado. Revista Iberoamericana de Educación, 38, Recuperado de http://rieoei.org/ deloslectores/1248Gonzalez.pdf

Hernández, R., Fernández, C., y Baptista, M. D. (2010). Metodología de la investigación (5ª ed.). México: McGraw Hill.

López-Calva, J. M. (2009a). Educación humanista. Una nueva visión de la educación desde la aportación de Bernard Lonergan y Edgar Morin. Tomo 1. México: Gernika.

López-Calva, J. M. (2009b). Educación humanista. Una nueva visión de la educación desde la aportación de Bernard Lonergan y Edgar Morin. Tomo 2. México: Gernika.

López, W. O. (2013). El estudio de casos: Una vertiente para la investigación educativa. Educere, 17(56), 139-144.

Mata, A. (2002). La educación superior en América Latina ante los retos del contexto actual. Revista Educación, 26(2), 29-30.

Maturana, A., y Varela, F. (2009). El árbol del conocimiento. Las bases biológicas del entendimiento humano (19a ed.). Santiago de Chile: Editorial Universitaria.

Meccia, E. (2007). Crónicas de un mundo pequeño. Una aplicación de la teoría fundamentada para el análisis de trayectorias de travestis en situación de prostitución. En S. Masseroni (Comp.), Interpretando la experiencia. Estudios cualitativos en Ciencias Sociales (pp. 99-152). Buenos Aires, Argentina: Mnemosyne.

Montes, D., y Suárez, C. (2016). La formación docente universitaria: Claves formativas de universidades españolas. REDIE. Revista Electrónica de Investigación Educativa, 18(3), 51-64.

Morales, M. D. (2013). Construir la legitimidad. Estrategias de una institución de educación superior privada. México: ANUIES.

Neiman, G., y Quaranta, G. (2006). Los estudios de caso en la investigación sociológica. En I. Vasilachis (Coord.), Estrategias de investigación cualitativa (pp. 213-237). Barcelona, España: Gedisa.

Ruffinelli, A. (2017). Formación de docentes reflexivos: Un enfoque en construcción y disputa. Educação e Pesquisa, 43(1), 97-111.

Salas, F. E. (2016). Aportes del modelo de Yrjö Engeström al desarrollo teórico de la docencia universitaria. Revista Educación, 40(2), 1-22.

Stake, R. E. (1999). Investigación con estudio de casos (2a ed.). Madrid, España: Morata.

Strauss, A., y Corbin, J. (2002). Bases de la investigación cualitativa. Técnicas y procedimientos para desarrollar la teoría fundamentada. Medellín, Colombia: Universidad de Antioquía.

UNESCO. (1998). Conferencia Mundial sobre la Educación Superior. La educación superior en el siglo XXI. Visión y acción. París, Francia: UNESCO.

Venegas, M. E. (2004). El concepto pedagógico 'Formación' en el universo semántico de la educación. Revista Educación, 28(2), 13-28.

Villaseñor, G. (2004). La función social de la educación superior en México. México: UAM-UNAM-UV.

Walker, S. V. (2016). El trabajo docente en la universidad: Condiciones, dimensiones y tensiones. Perfiles Educativos, 38(153), 105-119.

Yurén, M. T. (2005). Ethos y autoformación en los dispositivos de formación de docentes. En M. T. Yurén, C. Navia, y C. Saenger (Coords.), Ethos y autoformación docente. Análisis de dispositivos de formación de profesores (pp. 19-45). Barcelona, España: Pomares. 
José Francisco 1 Alanís Jiménez. Consideraciones para la formación continua de Personal docente un...

Yurén, M. T., Araújo, S., y García, O. (2003). La formación cívica y ética en secundarias. Un examen crítico. (Reporte final de investigación). En Consejo Mexicano de Investigación Educativa. Memoria Electrónica (CD-ROM) del VIII Congreso Nacional de Investigación Educativa. Hermosillo, México: COMIE.

Zabalza, M. Á., y Zabalza, M. A. (2012). Profesores y profesión docente. Entre el 'ser' y el 'estar'. Madrid, España: Narcea.

Zemelman, H. (1987). Conocimiento y sujetos sociales. México: Colegio de México.

Santillán, V. E., Viloria, E., y Cordero, G. (2013). Formación y procesos sociohistóricos e institucionales: Universidades. En P. Ducoing, y B. Fortoul (Edits.), Procesos de formación (volumen I. 2002-2011, pp. 261-308). México: ANUIES-COMIE.

CC BY-NC-ND 